\title{
An evaluation of seasonal variations in footwear worn by adults with inflammatory arthritis: a cross-sectional observational study using a web-based survey
}

\author{
Angela Brenton-Rule ${ }^{1 *}$, Gordon J Hendry ${ }^{2}$, Georgina Barr ${ }^{1}$ and Keith Rome ${ }^{1}$
}

\begin{abstract}
Background: Foot problems are common in adults with inflammatory arthritis and therapeutic footwear can be effective in managing arthritic foot problems. Accessing appropriate footwear has been identified as a major barrier, resulting in poor adherence to treatment plans involving footwear. Indeed, previous New Zealand based studies found that many people with rheumatoid arthritis and gout wore inappropriate footwear. However, these studies were conducted in a single teaching hospital during the New Zealand summer therefore the findings may not be representative of footwear styles worn elsewhere in New Zealand, or reflect the potential influence of seasonal climate changes. The aim of the study was to evaluate seasonal variations in footwear habits of people with inflammatory arthritic conditions in New Zealand.
\end{abstract}

Methods: A cross-sectional study design using a web-based survey. The survey questions were designed to elicit demographic and clinical information, features of importance when choosing footwear and seasonal footwear habits, including questions related to the provision of therapeutic footwear/orthoses and footwear experiences.

Results: One-hundred and ninety-seven participants responded who were predominantly women of European descent, aged between 46-65 years old, from the North Island of New Zealand. The majority of participants identified with having either rheumatoid arthritis (35\%) and/or osteoarthritis (57\%) and 68\% reported established disease ( $>5$ years duration). $18 \%$ of participants had been issued with therapeutic footwear. Walking and athletic shoes were the most frequently reported footwear type worn regardless of the time of year. In the summer, $42 \%$ reported wearing sandals most often. Comfort, fit and support were reported most frequently as the footwear features of greatest importance. Many participants reported difficulties with footwear (63\%), getting hot feet in the summer (63\%) and the need for a sandal which could accommodate a supportive insole (73\%).

Conclusions: Athletic and walking shoes were the most popular style of footwear reported regardless of seasonal variation. During the summer season people with inflammatory arthritis may wear sandals more frequently in order to accommodate disease-related foot deformity. Healthcare professionals and researchers should consider seasonal variation when recommending appropriate footwear, or conducting footwear studies in people with inflammatory arthritis, to reduce non-adherence to prescribed footwear.

Keywords: Footwear, Pain, Adherence, Comfort, Seasonal variation, Inflammatory arthritis

\footnotetext{
* Correspondence: abrenton@aut.ac.nz

'Division of Rehabilitation \& Occupation Studies, AUT University, Private Bag 92006, Auckland 1020, New Zealand

Full list of author information is available at the end of the article
} 


\section{Background}

Inflammatory arthritis affects more than 500,000 New Zealanders [1]. Foot problems are commonly associated with adult arthritic conditions, particularly with rheumatoid arthritis (RA) [2,3] and other inflammatory arthritic conditions such as gout [4], systemic sclerosis [5], psoriatic arthropathy [6], systemic lupus erythematous [7] and osteoarthritis (OA) [8]. Progressive foot problems affect up to $90 \%$ of patients with established RA $[2,3]$ and up to $70 \%$ of initial gout flares occur in the first metatarsophalangeal joint of the foot [9]. Patients with inflammatory arthritis have complex needs and foot problems can be inadequately understood or overlooked during consultations [3] despite previous studies which suggest that non-pharmacological interventions can reduce pain and disability and improve long-term outcomes for patients with existing and potential foot problems [10-12].

Podiatrists are often integrated members of multidisciplinary rheumatology teams and deliver foot care comprised of palliative skin and nail care, wound care, orthotic management, and therapeutic footwear $[13,14]$. Therapeutic footwear, whether it is off-the-shelf, custommade or retail, has been shown to be effective in managing foot problems associated with RA $[11,15,16]$, and may reduce foot pain and musculoskeletal disability in people with gout [10]. A previous study has shown that for people with RA, comfort and fit are reported as the major factors that influence footwear choice [17]. Further, patients with gout report that comfort, fit, provision of support, and cost are the main influencing factors over their footwear choices [18]. However, difficulties can develop where structural foot changes attributable to the arthritis progression make it problematic for patients to find appropriate shoes that are capable of accommodating their foot deformities. Martini et al. [19] reported that people with gout, who experienced symptoms in their lower extremities, were unable to put their shoes on or walk with ease and subsequently stayed at home. To get around the home, they limped, used crutches, or relied on family support to be mobile [19]. For people with RA-related foot problems, footwear difficulties can be the source of considerable distress and reinforce negative feelings associated with arthritic foot changes [15].

Appropriate footwear for people with inflammatory arthritis has been identified as a major barrier relating to adherence to treatment plans involving prescribed footwear $[15,20,21]$. Previous studies looking at footwear characteristics associated with RA [17] and gout [18] in New Zealand, also found that many people wore inappropriate footwear. In the case of gout, this was in part due to the financial limitations of those affected by the illness [18]. However, these studies lacked external validity as patients were recruited from one large teaching hospital during the summer months only. Therefore, these findings may not be a true representation of footwear styles worn elsewhere in New Zealand, nor do they capture the potential influence of seasonal climate changes. A qualitative study of people with RA in Australia found that higher temperatures experienced during summer may play a key role in influencing footwear habits [20]. Moreover, further qualitative research conducted in the UK identified the frustration amongst women with RA due to their inability to follow seasonal footwear trends [22]. The current research consists of a nationwide survey which aims to identify the features of importance when choosing footwear and the type of footwear worn by people with inflammatory arthritis during the winter and summer months. The aim was to survey footwear habits of people with inflammatory arthritic conditions in New Zealand and to identify any seasonal variation.

\section{Methods}

A cross-sectional observational study design using a web-based survey was used. Participants were a convenience sample of adults who were identified as having inflammatory arthritis. The survey was promoted by Arthritis New Zealand. Currently, over 4000 members of Arthritis New Zealand have been registered as having inflammatory joint disease including RA, gout, psoriatic arthritis, osteoarthritis, systemic lupus erythematous, juvenile idiopathic arthritis, fibromyalgia, systemic sclerosis/scleroderma and spondyloarthropathy. According to Arthritis New Zealand, approximately $10 \%$ of members use emails therefore providing a total target sample of 400 participants who subsequently received an invitation to participate [23]. A response rate of 30-50\% (120-200 participants) was anticipated $[24,25]$. Ethical approval was obtained from Auckland University of Technology Ethics Committee (AUTEC). The survey was anonymous and self-administered.

\section{Survey development}

The survey was developed and subject to pilot testing by all co-authors to ensure the relevance of the questions, and the final questionnaire was amended according to feedback. Three iterative revisions were conducted by the research team and these were based upon previous research [20], clinical experience, and current foot care recommendations [13-15]. The survey which was comprised of 18 questions was pilot-tested on five people with inflammatory arthritis and all co-authors. All coauthors agreed on the final version. Questions 1-5 were to elicit demographic information that included age, gender, New Zealand region of residence, ethnicity and current work status. Questions 6-8 sought to obtain information relating to current inflammatory arthritic condition, disease duration and current foot pain. Question 9 sought to elicit participant reports of the most important 
Table 1 Participant demographic and disease characteristics

\begin{tabular}{|c|c|c|c|c|c|c|c|}
\hline & Male & Female & Total & Has footwear from Orthotics & $8(33)$ & $23(15)$ & $31(18)$ \\
\hline Gender, no. (\%) & $29(16)$ & $156(84)$ & $185(100)$ & Centre, no. $(\%)^{*}$ & & & \\
\hline Age groups, no. (\%) & & & & Wears footwear from Orthotics & & & \\
\hline $16-25$ years & $1(3)$ & $5(3)$ & $6(3)$ & Centre, no. (\%) & & & \\
\hline $26-35$ years & $4(14)$ & $9(6)$ & $13(7)$ & All the time & $3(38)$ & $5(22)$ & $8(26)$ \\
\hline $36-45$ years & $4(14)$ & $13(8)$ & $17(9)$ & Occasionally & $3(38)$ & $11(48)$ & $14(45)$ \\
\hline $45-65$ years & $6(21)$ & $73(47)$ & $79(43)$ & Never & $2(25)$ & $7(30)$ & $9(29)$ \\
\hline $66-75$ years & $9(31)$ & $39(25)$ & $48(26)$ & $\begin{array}{l}\text { Receives regular podiatry } \\
\text { treatment, no. }(\%)^{*}\end{array}$ & $6(25)$ & $42(28)$ & $48(28)$ \\
\hline Over 75 years & $5(17)$ & $17(11)$ & $22(12)$ & Last visited a podiatrist, no. $(\%)^{*}$ & & & \\
\hline Ethnicity, no. (\%) & & & & Less than 1 month & $2(8)$ & $16(11)$ & $18(10)$ \\
\hline Maori & $1(3)$ & $5(3)$ & $6(3)$ & $1-2$ months & $0(0)$ & $6(4)$ & $6(3)$ \\
\hline European & $27(93)$ & $142(91)$ & $169(91)$ & 3-6 months & $4(17)$ & $20(13)$ & $24(14)$ \\
\hline Pacific Islander & $1(3)$ & $2(1)$ & $3(2)$ & 7-12 months & $3(13)$ & $12(8)$ & $15(9)$ \\
\hline Asian & $0(0)$ & $7(4)$ & $7(4)$ & 13-24 months & $2(8)$ & $13(9)$ & $15(9)$ \\
\hline Geographic location, no. (\%) & & & & More than 2 years ago & $4(17)$ & $42(28)$ & $46(27)$ \\
\hline North Island & $21(72)$ & $105(67)$ & $126(68)$ & Never & $9(37)$ & $40(27)$ & $49(28)$ \\
\hline South Island & $8(28)$ & $51(33)$ & $59(32)$ & $n=173$. & & & \\
\hline
\end{tabular}

Employment status, no. (\%)

Employed

$12(41) \quad 76(49) \quad 88(48)$

Voluntary work

Unemployed

Retired

On a benefit

Arthritic condition, no. (\%)

Rheumatoid Arthritis

Gout

Systemic Sclerosis

Fibromyalgia

Lupus

Osteoarthritis

Juvenile Idiopathic Arthritis

Psoriatic Arthritis

Spondyloarthropathy

Other

Disease duration, no. (\%)

6 weeks to 6 months

6 months to 1 year

1-5 years

5-10 years

More than 10 years

Foot Pain VAS (0-10), mean (SD)

Insoles or orthotics prescribed by podiatrist or other healthcare professional, no. (\%)*
Table 1 Participant demographic and disease characteristics (Continued)

features to them when choosing footwear and the presented response options were based upon previous studies $[17,18,26]$. Questions 10 and 11 were designed to elicit information related to participants' current footwear style most frequently worn during winter and summer months. A list of 14 styles of footwear was provided [27], with the addition of barefoot and socks. Participants were asked to rate how often they wear each footwear type (Never, Sometimes, Mostly, Always). Questions 12-16 relate to the role of healthcare professionals in providing footwear and foot orthoses. Question 17 was designed according to statements obtained from a previous study of people with rheumatoid arthritis in order to determine respondents' previous experiences of footwear [20]. Participants had the opportunity at the end of the survey to make open-ended comments regarding their experience of footwear in relation to their arthritic condition (Question 18).

The survey utilised the online software, Survey Monkey ${ }^{\circ}$ http://www.surveymonkey.com. This software allows users to self-create surveys and is easy to use with a large set of features [25]. Online surveys have the advantages of timeefficiency, reduced cost, automated data collection and an ability to overcome distance barriers in participant data collection $[28,29]$. A hyperlink to the survey was placed on the Arthritis New Zealand website. The survey was open for approximately ten weeks between December 2013 and February 2014.

\section{Data analysis}

Data were analysed using Statistical Package for Social Sciences (SPSS) V22.0 (IBM Corp., New York, USA). 
The primary analysis was descriptive statistics summarising survey results. Data from Survey Monkey were manually entered into SPSS by one researcher (GB).

\section{Results}

One-hundred and ninety-seven people responded to the survey. Twelve respondents were removed as they only completed questions related to demographic information.

\section{Demographics and clinical characteristics}

The demographic and clinical characteristics are summarised in Table 1. The survey respondents were predominately women of European descent, aged between 46-65 years old, from the North Island of New Zealand. The majority reported having RA $(n=65,35 \%)$ and/or OA $(\mathrm{n}=106,57 \%)$, and $68 \%(\mathrm{n}=125)$ reported having established disease ( $>5$ years duration). Nearly half $(\mathrm{n}=$ $88,48 \%$ ) were in employment, $40 \%$ were retired and $16 \%$ were unemployed or involved in voluntary work. Over two thirds $(\mathrm{n}=125,72 \%)$ of respondents did not receive regular podiatric care, although $67 \%(\mathrm{n}=116)$ had been previously prescribed with insoles or orthotics from a health professional. Further, 18\% of participants had been issued with therapeutic footwear from a private organisation contracted by the New Zealand government to provide footwear and orthoses to high-risk patients. Of those provided with therapeutic footwear, nearly one third $(n=9,29 \%)$ reported that they do not wear their prescribed footwear and 45\% $(n=14)$ reported that they wear only them occasionally.

\section{Seasonal footwear habits, features of importance and experience of footwear}

Table 2 demonstrates the frequency of footwear types reported by respondents as having been worn during the winter and summer months. Walking and athletic shoes were reported as the most frequently worn footwear type regardless of the season. In the summer, $42 \%$ of participants reported wearing sandals most often and $22 \%$ reported going barefoot most often. In winter, $20 \%$ of participants reported wearing boots while $26 \%$ reported wearing slippers most often. Table 3 presents participant responses related to the features that may be of importance to them when choosing footwear. Comfort, fit and support were frequently reported as being very important factors when choosing footwear. Colour was reported as the least important footwear attribute. Heel height was reported as very important by $54 \%$ of participants but $11 \%$ reported heel height as unimportant. Table 4 summarises agreement with statements previously made by people with arthritis, regarding their footwear experiences. Participants (63\%) reported that they had difficulties with shoes (statement 1 ). The majority of respondents $(63 \%)$ agreed with getting hot feet in the
Table 2 Type of footwear worn by respondents*

\begin{tabular}{|c|c|c|c|c|c|}
\hline & & Never & Sometimes & Mostly & Always \\
\hline \multirow{16}{*}{$\begin{array}{l}\text { Winter, } \\
\text { no. (\%) }\end{array}$} & Sandal & $146(82)$ & $30(17)$ & $1(0.6)$ & $1(0.6)$ \\
\hline & Mule & 166 (93) & $10(6)$ & $2(1)$ & - \\
\hline & $\begin{array}{l}\text { Jandals/ } \\
\text { Flip-Flops }\end{array}$ & $146(82)$ & $27(15)$ & $3(2)$ & $2(1)$ \\
\hline & Walking shoe & $38(21)$ & $49(28)$ & $64(36)$ & $27(15)$ \\
\hline & Athletic shoe & $25(14)$ & $65(37)$ & $64(36)$ & $24(14)$ \\
\hline & Moccasin & $149(84)$ & $23(13)$ & $6(3)$ & - \\
\hline & Oxford shoe & $143(80)$ & $22(12)$ & $12(7)$ & $1(0.6)$ \\
\hline & $\begin{array}{l}\text { Therapeutic } \\
\text { shoe }\end{array}$ & $150(84)$ & $13(7)$ & $8(5)$ & $7(4)$ \\
\hline & Boot & $78(44)$ & $64(36)$ & $29(16)$ & $7(4)$ \\
\hline & Ugg Boot & $147(83)$ & $21(12)$ & $5(3)$ & $5(3)$ \\
\hline & High Heel & 159 (89) & $17(10)$ & $2(1)$ & - \\
\hline & Court shoe & $99(56)$ & $65(37)$ & $13(7)$ & $1(0.6)$ \\
\hline & Slipper & $55(31)$ & $77(43)$ & $33(19)$ & $13(7)$ \\
\hline & Backless slipper & $135(76)$ & $24(14)$ & $14(8)$ & $5(3)$ \\
\hline & Socks & $91(51)$ & $66(37)$ & $16(9)$ & $5(3)$ \\
\hline & Barefoot & $123(69)$ & $47(26)$ & $7(4)$ & $1(0.6)$ \\
\hline \multirow{16}{*}{$\begin{array}{l}\text { Summer, } \\
\text { no. (\%) }\end{array}$} & Sandal & $34(19)$ & $67(39)$ & $62(36)$ & $10(6)$ \\
\hline & Mule & $157(91)$ & $14(8)$ & $2(1)$ & - \\
\hline & $\begin{array}{l}\text { Jandals/ } \\
\text { Flip-Flops }\end{array}$ & $94(54)$ & $52(30)$ & $19(11)$ & $8(5)$ \\
\hline & Walking shoe & $45(26)$ & $62(36)$ & $49(28)$ & $17(10)$ \\
\hline & Athletic shoe & $25(15)$ & $71(41)$ & $60(35)$ & $17(10)$ \\
\hline & Moccasin & $157(91)$ & $14(8)$ & $2(1)$ & - \\
\hline & Oxford shoe & $151(87)$ & $15(9)$ & $6(4)$ & $1(0.6)$ \\
\hline & $\begin{array}{l}\text { Therapeutic } \\
\text { shoe }\end{array}$ & 154 (89) & $13(8)$ & $5(3)$ & $1(0.6)$ \\
\hline & Boot & $139(80)$ & $27(16)$ & $6(4)$ & $1(0.6)$ \\
\hline & Ugg Boot & 165 (95) & $8(5)$ & - & - \\
\hline & High Heel & $153(88)$ & $19(11)$ & $1(0.6)$ & - \\
\hline & Court shoe & $97(56)$ & 67 (39) & $7(4)$ & $2(1)$ \\
\hline & Slipper & $86(50)$ & $69(40)$ & $15(9)$ & $3(2)$ \\
\hline & $\begin{array}{l}\text { Backless } \\
\text { slipper }\end{array}$ & $129(75)$ & 33 (19) & $10(6)$ & $1(0.6)$ \\
\hline & Socks & $103(60)$ & $59(34)$ & $10(6)$ & $1(0.6)$ \\
\hline & Barefoot & $59(34)$ & $77(45)$ & $32(19)$ & $5(3)$ \\
\hline
\end{tabular}

${ }^{*} n=178$ responses for footwear worn in winter, $n=173$ responses for footwear worn in summer.

summer (statement 2) and the need for a sandal which could take a supportive insole (73\%) (statement 5). The depth (statement 3 ) and width (statement 4) of the shoe were of less concern to participants. Eighty-five participants $(46 \%)$ provided open-ended comments in relation to their footwear experiences (Question 18). Comments related to difficulties in finding appropriate footwear, 
Table 3 Features of importance when choosing footwear, no. $(\%)$

\begin{tabular}{lllll}
\hline & Not important & $\begin{array}{l}\text { Slightly } \\
\text { important }\end{array}$ & Of importance & $\begin{array}{l}\text { Very } \\
\text { important }\end{array}$ \\
\hline Comfort & - & - & $16(9)$ & $169(91)$ \\
Style & $15(8)$ & $49(27)$ & $89(48)$ & $32(17)$ \\
Fit & - & - & $21(11)$ & $164(89)$ \\
Support & $3(2)$ & $7(4)$ & $36(19)$ & $139(75)$ \\
Cost & $13(7)$ & $41(22)$ & $87(47)$ & $44(24)$ \\
Weight & $9(5)$ & $51(28)$ & $77(42)$ & $48(26)$ \\
Colour & $22(12)$ & $58(31)$ & $78(42)$ & $27(15)$ \\
Material & $11(6)$ & $47(25)$ & $85(46)$ & $42(23)$ \\
Fastenings & $16(9)$ & $43(23)$ & $73(39)$ & $53(29)$ \\
Nonslip & $8(4)$ & $30(16)$ & $54(29)$ & $93(50)$ \\
Heel & $20(11)$ & $14(8)$ & $51(28)$ & $100(54)$ \\
height & & & & \\
Ease to & $6(3)$ & $24(13)$ & $60(32)$ & $95(51)$ \\
put on & & & & \\
\hline
\end{tabular}

dissatisfaction with footwear service provision, high cost of footwear and satisfaction/relief with eventual receipt of appropriate footwear.

\section{Discussion}

The aim of the study was to determine the seasonal influences on footwear habits in people with inflammatory arthritis in New Zealand. Previous qualitative studies highlighted issues around seasonal footwear choices for people with RA-related foot problems [20,22]. To our knowledge, the current findings are the first to report seasonal influences on the footwear worn by people with inflammatory arthritis.

We found that therapeutic footwear was reported as being worn by a small number of participants regardless of the season. Despite the benefits of therapeutic footwear $[11,16]$ this type of footwear was not widely worn by patients in the current study. Additionally there are known factors relating to poor use of therapeutic footwear and reasons why therapeutic footwear is deemed to be unacceptable [15,20,21]. Williams et al. [15] identified therapeutic footwear as being the only intervention that replaces something that is normally worn as an item of clothing and therefore reinforces the stigma of foot deformity and disability. In addition to body image issues, Hendry et al. [20] reported that patients feet become over-heated in closed in therapeutic footwear, and Otter et al. [21] reported that some patients discontinued using therapeutic footwear either because their foot symptoms had resolved or because they had foot surgery. Adherence to podiatric intervention strategies, in particular therapeutic footwear, appears to be an important consideration in inflammatory arthritis. There is good evidence to suggest that healthcare priorities and preferences of care provided are different for patients who have arthritis [30]. Awareness of these issues has the potential to improve patient care through shared clinical decision making [31,32]. Issues with non-adherence to therapeutic footwear has previously been reported in studies from the USA [33], UK [21,34], Turkey [35], Australia [36], The Netherlands and Spain [37].

In evaluating footwear worn in winter and summer, we found that athletic and walking shoes were the most popular style reported regardless of season. Athletic and walking shoes have been reported as the most comfortable option for people with RA [38], OA [39] and gout $[10,18]$. A previous study reported that athletic shoes were an acceptable alternative to off-the-shelf therapeutic or orthopaedic footwear for people with RArelated forefoot pain [40], suggesting that healthcare professionals should consider walking and athletic shoes for routine footwear advice in people with inflammatory arthritic conditions.

The most striking seasonal difference was the wearing of sandals, which were reported as being worn frequently by $42 \%$ of respondents during the summer. Previous studies have reported similar findings $[17,41,42]$, and may be in part due to forefoot structural deformities, severe bunions and clawing of the lesser toes often observed in inflammatory arthritic conditions. Sandals are defined as shoes with a sole that is fastened to the foot by thongs or straps [17]. Despite the availability of good quality sandals, nearly three-quarters of respondents

Table 4 Statements made about footwear experiences, no. (\%)

\begin{tabular}{|c|c|c|c|c|c|}
\hline & & $\begin{array}{l}\text { Strongly } \\
\text { disagree }\end{array}$ & Disagree & Agree & $\begin{array}{l}\text { Strongly } \\
\text { agree }\end{array}$ \\
\hline 1 & "I do have a lot of trouble with shoes; I have to have shoes that are very, very soft." & $17(10)$ & $46(27)$ & $77(46)$ & $29(17)$ \\
\hline 2 & $\begin{array}{l}\text { "In the summer I want my feet to breathe. It's getting hot in the shoes, so I don't wear } \\
\text { them in the summer." }\end{array}$ & $15(9)$ & $48(28)$ & $85(50)$ & $22(13)$ \\
\hline 3 & $\begin{array}{l}\text { "The biggest problem I had getting shoes was the depth in the shoes, they weren't } \\
\text { tall enough around the toe area to accommodate the claw toes." }\end{array}$ & $46(27)$ & $63(37)$ & $42(24)$ & $20(12)$ \\
\hline 4 & "I've had to go up 1 shoe size and I'm like a double to triple fitting in the shoes." & $40(24)$ & $61(36)$ & $52(30)$ & $17(10)$ \\
\hline 5 & $\begin{array}{l}\text { "Someone should invent a sandal that will take the insole and support your foot. . . } \\
\text { You put up with your feet being roasted in the summer." }\end{array}$ & $15(9)$ & $31(18)$ & $70(41)$ & $55(32)$ \\
\hline
\end{tabular}


agreed with the statement "Someone should invent a sandal that will take the insole and support your foot...". This may indicate a lack of awareness of the more supportive, higher quality sandals that are commercially available. It is also possible that the cost of high quality supportive or orthotic-friendly sandals is a prohibitive factor for many people with arthritic conditions $[17,18,20]$.

In the current study, participants reported that comfort, fit and support were reported as the most important features when choosing footwear, and the majority of participants agreed with statements regarding the need for a softer and more supportive shoe. Previous studies in people with RA $[17,26]$ and gout [18] also reported that comfort, fit and support were important, which may suggest that people with inflammatory arthritis prioritise these features due to disease-related foot problems. The majority of respondents also agreed with statements regarding the feet overheating in closed-in footwear during the summer. The provision of publically funded therapeutic sandals and education regarding the availability of high quality, supportive, commercially available sandals, may be warranted.

The study has limitations. The study was undertaken in New Zealand and may not reflect footwear trends in other developed countries. The survey was only available electronically thus excluding those without access to a computer or internet connection. Therefore the results may not be representative of the wider population with inflammatory arthritis in New Zealand. The elicitation of self-reported responses does not necessarily represent 'actual' footwear habits/experiences, but rather respondents' opinions/perceptions of their habits at the time of survey completion. Given the reported popularity of wearing athletic shoes, walking shoes and sandals in people with inflammatory arthritis, further research investigating the long term effects of commercially available footwear on foot pain, impairment and disability may be warranted.

\section{Conclusions}

The current findings are the first to report seasonal influences on the footwear habits of people with inflammatory arthritic conditions. Therapeutic footwear was reported as being worn by a small number of participants regardless of the season and may reflect issues with adherence, body image, fit and comfort. Athletic and walking shoes were the most popular style regardless of season and may reflect people with inflammatory arthritic conditions choice of footwear. The wearing of sandals was popular during the summer that suggests people with inflammatory arthritis wear sandals in order to better accommodate forefoot deformity and associated pain, impairment and disability. The popularity of sandals may also be due to feet getting hot in closed-in footwear and education is needed regarding the availability of high quality orthotic-friendly sandals. Healthcare professionals should be aware of seasonal variations in footwear worn by people with inflammatory arthritis and assist their patients in accessing appropriate footwear to reduce non-adherence.

\section{Competing interests}

The authors declare that they have no competing interests.

\section{Authors' contributions}

$\mathrm{KR}$ and $\mathrm{GH}$ conceived the study protocol. $\mathrm{KR}, \mathrm{GH}$ and $\mathrm{GB}$ designed the survey. GB piloted and finalised the survey and inputted the data. ABR conducted the statistical analysis and $A B R, K R$ and $G H$ interpreted the findings. $A B R, K R$ and $G H$ drafted the manuscript with input from $G B$ and the final version was read and approved by all co-authors.

\section{Acknowledgments}

GB was supported through a summer studentship research grant from Arthritis New Zealand. Footwear images in the on-line survey courtesy of Christian J Barton, Daniel Bonanno and Hylton B Menz. Development and evaluation of a tool for the assessment of footwear characteristics. J Foot Ankle Res. 2009; 2:10.

\section{Author details}

${ }^{1}$ Division of Rehabilitation \& Occupation Studies, AUT University, Private Bag 92006, Auckland 1020, New Zealand. ${ }^{2}$ School of Health and Life Sciences, Glasgow Caledonian University, Cowcaddens Rd, Glasgow, Lanarkshire G4 OBA, UK.

Received: 2 June 2014 Accepted: 1 August 2014

Published: 13 August 2014

\section{References}

1. A Portrait Of Health: Key Results Of The 2006/2007 New Zealand Health Survey. http://www.health.govt.nz/publication/portrait-health-key-results2006-07-new-zealand-health-survey.

2. National Collaborating Centre for Chronic Conditions: Rheumatoid Arthritis: National Clinical Guideline For Management And Treatment In Adults. London: Royal College of Physicians; 2009.

3. Rome K, Chapman J, Williams AE, Gow P, Dalbeth N: Podiatry services for patients with arthritis: an unmet need. N Z Med J 2010, 123:91-97.

4. Rome K, Survepalli D, Sanders A, Lobo M, McQueen FM, McNair P, Dalbeth $\mathrm{N}$ : Functional and biomechanical characteristics of foot disease in chronic gout: a case-control study. Clin Biomech 2011, 26(1):90-94

5. Alcacer-Pitarch B, Siddle HJ, Buch MH, Emery P, Hashmi F, Redmond AC: Foot health needs in people with systemic sclerosis: an audit of foot health care provision. Clin Rheumatol 2011, 30(12):1611-1615.

6. Hyslop E, Mclnnes I, Woodburn J, Turner D: Foot problems in psoriatic arthritis: high burden and low care provision. Ann Rheum Dis 2010, 69(5):928-928.

7. Williams A, Crofts G, Teh L: 'Focus on feet'-the effects of systemic lupus erythematosus: a narrative review of the literature. Lupus 2013, 22(10):1017-1023

8. Roddy E, Thomas MJ, Marshall M, Rathod T, Myers H, Menz HB, Thomas E, Peat G: The population prevalence of symptomatic radiographic foot osteoarthritis in community-dwelling older adults: cross-sectional findings from the clinical assessment Study of the Foot. Ann Rheum Dis 2013, 0:1-8. doi:10.1136/annrheumdis-2013-203804.

9. Wright SA, Filippucci E, McVeigh C, Grey A, McCarron M, Grassi W, Wright GD, Taggart AJ: High-resolution ultrasonography of the first metatarsal phalangeal joint in gout: a controlled study. Ann Rheum Dis 2007, 66(7):859-864.

10. Rome K, Stewart S, Vandal AC, Gow P, McNair P, Dalbeth N: The effects of commercially available footwear on foot pain and disability in people with gout: a pilot study. BMC Musculoskelet Disord 2013, 14(1):278

11. Williams $A E$, Rome $K$, Nester CJ: A clinical trial of specialist footwear for patients with rheumatoid arthritis. Rheumatology 2007, 46(2):302-307.

12. Woodburn J, Hennessy K, Steultjens MP, McInnes IB, Turner DE: Commentary looking through the 'window of opportunity': is there a 
new paradigm of podiatry care on the horizon in early rheumatoid arthritis? J Foot Ankle Res 2010, 3:8

13. Rome K, Erikson K, Ng A, Gow PJ, Sahid H, Williams AE: A new podiatry service for patients with arthritis. N Z Med J 2013, 126:70-77.

14. Williams AE, Davies S, Graham A, Dagg A, Longrigg K, Lyons C, Bowen C: Guidelines for the management of the foot health problems associated with rheumatoid arthritis. Musculoskeletal Care 2011, 9(2):86-92

15. Williams AE, Nester CJ, Ravey MI: Rheumatoid arthritis patients' experiences of wearing therapeutic footwear-a qualitative investigation. BMC Musculoskelet Disord 2007, 8(1):104.

16. Dahmen R, RBuijsmann S, Siemonsma P, Boers M, Lankhorst G, Roorda L: Use and effects of custom-made therapeutic footwear on lower-extremity related pain and activity limitations in patients with rheumatoid arthritis: a prospective observational study of a cohort. J Rehabil Med 2014, 46(6):561-567. doi:10.2340/16501977-1807.

17. Silvester RN, Williams AE, Dalbeth N, Rome K: 'Choosing shoes': a preliminary study into the challenges facing clinicians in assessing footwear for rheumatoid patients. J Foot Ankle Res 2010, 3:24.

18. Rome K, Frecklington M, Mcnair P, Gow P, Dalbeth N: Footwear characteristics and factors influencing footwear choice in patients with gout. Arthritis Care Res 2011, 63(11):1599-1604.

19. Martini N, Bryant L, Te Karu L, Aho L, Chan R, Miao J, Naidoo C, Singh H, Tieu A: Living with gout in New Zealand: an exploratory study into people's knowledge about the disease and its treatment. J Clin Rheumatol 2012, 18(3):125-129.

20. Hendry GJ, Gibson KA, Pile K, Taylor L, Du Toit V, Burns J, Rome K: "They just scraped off the calluses": a mixed methods exploration of foot care access and provision for people with rheumatoid arthritis in south-western Sydney, Australia. J Foot Ankle Res 2013, 6:34

21. Otter S, Lucas K, Springett K, Moore A, Davies K, Cheek L, Young A, Walker-Bone K: Foot pain in rheumatoid arthritis prevalence, risk factors and management: an epidemiological study. Clin Rheumatol 2010, 29(3):255-271.

22. Naidoo S, Anderson S, Mills J, Parsons S, Breeden S, Bevan E, Edwards C, Otter S: "I could cry, the amount of shoes I can't get into": a qualitative exploration of the factors that influence retail footwear selection in women with rheumatoid arthritis. J Foot Ankle Res 2011, 4:21.

23. Arthritis New Zealand Website. http://www.arthritis.org.nz.

24. Nulty DD: The adequacy of response rates to online and paper surveys: what can be done? Assess Eval High Educ 2008, 33(3):301-314.

25. Sue VM, Ritter LA: Conducting Online Surveys. Thousand Oaks, California: Sage; 2007.

26. Williams A, Nester C: Patient perceptions of stock footwear design features. Prosthet Orthot Int 2006, 30(1):61-71.

27. Menz HB, Sherrington $C$ : The footwear assessment form: a reliable clinical tool to assess footwear characteristics of relevance to postural stability in older adults. Clin Rehabil 2000, 14(6):657-664.

28. Bryman A: Social research methods. New York: Oxford University Press; 2012.

29. Oppenheimer AJ, Pannucci CJ, Kasten SJ, Haase SC: Survey says? A primer on Web-based survey design and distribution. Plast Reconstr Surg 2011, 128(1):299.

30. Kirwan JR, Hewlett SE, Heiberg T, Hughes RA, Carr M, Hehir M, Kvien TK, Minnock P, Newman SP, Quest EM: Incorporating the patient perspective into outcome assessment in rheumatoid arthritis-progress at OMERACT 7. J Rheumatol 2005, 32(11):2250-2256.

31. Heiberg T, Kvien TK: Preferences for improved health examined in 1,024 patients with rheumatoid arthritis: pain has highest priority. Arthritis Care Res 2002, 47(4):391-397.

32. Holman H, Lorig K: Patients as partners in managing chronic disease. BMJ 2000, 320(7234):526-527

33. Dufour AB, Broe KE, Nguyen USD, Gagnon DR, Hillstrom HJ, Walker AH, Kivell E, Hannan MT: Foot pain: is current or past shoewear a factor? Arthritis Care Res 2009, 61(10):1352-1358.

34. Williams AE, Bowden AP: Meeting the challenge for foot health in rheumatic diseases. Foot 2004, 14(3):154-158.

35. Borman P, Ayhan F, Tuncay F, Sahin M: Foot problems in a group of patients with rheumatoid arthritis: an unmet need for foot care. Open Rheumatol J 2012, 6:290.

36. Spink MJ, Menz HB, Fotoohabadi MR, Wee E, Landorf KB, Hill KD, Lord SR Effectiveness of a multifaceted podiatry intervention to prevent falls in community dwelling older people with disabling foot pain: randomised controlled trial. BMJ 2011, 342:d3411.
37. Williams AE, Nester CJ, Ravey MI, Kottink A, Morey-Klapsing G: Women's experiences of wearing therapeutic footwear in three European countries. J Foot Ankle Res 2010, 3(1):23.

38. Helliwell P, Woodburn J, Redmond A, Turner D, Davys H: The Foot And Ankle In Rheumatoid Arthritis: A Comprehensive Guide. Edinburgh, UK: Churchill Livingston; 2007.

39. Menz HB, Levinger P, Tan JM, Auhl M, Roddy E, Munteanu SE: Rocker-sole footwear versus prefabricated foot orthoses for the treatment of pain associated with first metatarsophalangeal joint osteoarthritis: study protocol for a randomised trial. BMC Musculoskelet Disord 2014, 15(1):86.

40. Hennessy K, Burns J, Penkala S: Reducing plantar pressure in rheumatoid arthritis: a comparison of running versus off-the-shelf orthopaedic footwear. Clin Biomech 2007, 22(8):917-923.

41. Brenton-Rule A, D'Almeida S, Bassett S, Carroll M, Dalbeth N, Rome K: The effects of sandals on postural stability in patients with rheumatoid arthritis: an exploratory study. Clin Biomech 2013, 29(3):350-353.

42. Rome K, Gow PJ, Dalbeth N, Chapman JM: Clinical audit of foot problems in patients with rheumatoid arthritis treated at Counties Manukau District Health Board, Auckland, New Zealand. J Foot Ankle Res 2009, 2:16.

doi:10.1186/s13047-014-0036-7

Cite this article as: Brenton-Rule et al: An evaluation of seasonal variations in footwear worn by adults with inflammatory arthritis: a cross-sectional observational study using a web-based survey. Journal of Foot and Ankle Research 2014 7:36.

\section{Submit your next manuscript to BioMed Central and take full advantage of:}

- Convenient online submission

- Thorough peer review

- No space constraints or color figure charges

- Immediate publication on acceptance

- Inclusion in PubMed, CAS, Scopus and Google Scholar

- Research which is freely available for redistribution

Submit your manuscript at www.biomedcentral.com/submit
C Biomed Central 